PARALLAX VISIONS 
ASIA-PACIFIC:

CULTURE, POLITICS, AND SOCIETY

Editors:

Rey Chow,

H. D. Harootunian,

and

Masao Miyoshi 


\title{
PARALLAX VISIONS
}

MAKING SENSE of AMERICAN-EAST ASIAN RELATIONS

\author{
Bruce Cumings
}

DUKE UNIVERSITY PRESS Durham \& London 2002 
First printing in paperback, 2002

(C) 1999 Duke University Press

All rights reserved

Printed in the United States of America on acid-free paper $\infty$

Typeset in Trump Mediaeval by Keystone

Typesetting, Inc.

Library of Congress Cataloging-in-Publication Data appear on the last printed page

of this book. 